\title{
Derivation of the unified equation of axial compression of CFST columns
}

\author{
Ruoyang Zhou ${ }^{1}$ and Xiaoxiong Zha ${ }^{1, *}$ \\ ${ }^{1}$ Shenzhen Graduate School, Harbin Institute of Technology, Shenzhen 518055, Guangdong, China
}

\begin{abstract}
The steel tube concrete columns with steel reinforcement cages, steel plates and steel tubes has been used in super high-rise buildings, which are called concrete-filled steel tubular (CFST) columns with internal stiffeners. Based on the theory of limit equilibrium, the unified equation for the axial bearing capacity of the CFST columns with internal stiffeners is obtained. The derived equation in this study can provide reference for the future engineering applications.
\end{abstract}

\section{Introduction}

As the height of the structure increases, the vertical load of the structure will inevitably increase. The ordinary concrete-filled steel tubular (CFST) columns cannot be pragmatic approach since they lack sufficient bearing capacity. CFST columns with novel cross section have been used in super high-rise building. Comparing with ordinary CFST columns, these types of columns have the following advantages: First, for the super-large section, the internal stiffeners can divide the section into multiple hollow section, which can effectively reduce the section size of the concrete column and prevent the unfavorable appearance of the large concrete cross section. Furthermore, these hollow sections form a composite peripheral constraint on concrete, which can improve the peripheral constraint and global ductility of concrete. Secondly, the section is polygonal which make it easier to fit the outer edge of the building and it is convenient for connecting the extended-arm truss and belt truss. Thirdly, the steel reinforcement cage of CFST columns is equal to additional concrete core columns which can improve the integrity of internal concrete and bearing capacity and the ductility of the columns.

An increasing number of studies have focused on the axial bearing capacity of CFST columns with internal stiffeners. The carried out experimental and theoretical research on the CFST columns with internal stiffeners [1-6] are provided theoretical basis and experimental data for this study. However, lack of unified equation for the axial bearing capacity of CFST columns with internal stiffeners endangers, the practical application of CFST columns in real word application. Therefore, a unified equation for investigating the axial bearing capacity of CFST columns with internal stiffeners that benefits from the limit equilibrium theory to derive the bearing capacity of the axial compression is proposed.

\section{Derivation of the equation for the axial compression}

In this study, the limit equilibrium theory [7] is used to derive the axial bearing capacity of CFST columns with internal stiffeners. The theory of limit equilibrium has been described in [8] and for the sake of brevity will not be repeated.

\subsection{Fundamental hypothesis}

The basic hypotheses have been described in [8], and content of hypothesis 2 in [8] are added in the following research.

The yield condition of steel tube and core concrete are constant and do not change with the development of plastic deformation. The core concrete bases on the linear yield condition can be expressed as

$$
\sigma_{\mathrm{c}}=f_{\mathrm{c}}\left(1+k \frac{p}{f_{\mathrm{c}}}\right)
$$

the yield condition of plastic materials are described by Tresca yield condition and Mises yield condition [9].

According to the mentioned conditions, maximum shear stress condition and distortion energy condition can be expressed as

(1) Tresca yield condition (three direction):

$$
\begin{aligned}
& \left|\sigma_{1}-\sigma_{3}\right| \leq 2 a, \\
& \left|\sigma_{1}-\sigma_{2}\right| \leq 2 a, \\
& \left|\sigma_{2}-\sigma_{3}\right| \leq 2 a,
\end{aligned}
$$

where, $\sigma_{1} 、 \sigma_{2} 、 \sigma_{3}$ are representing principal stresses; $a$ is a number which relates to the material and the test mode, in which if using the simple tensile test to determine the yield strength of the material, the equation is $a=f_{\mathrm{s}} / 2$, and

\footnotetext{
*Corresponding author: zhahero@,126.com
} 
if using the simple shear test to determine the yield strength of the material, the equation is $a=\sqrt{3} f_{\mathrm{s}} / 2$.

Tresca yield condition of the steel tube which is considering tension in the hoop direction and compression in the axial direction can be simplified to

$$
\left|\sigma_{1}+\sigma_{2}\right| \leq 2 a \text {. }
$$

(2) Mises yield condition can be expressed as

$$
\left(\sigma_{1}-\sigma_{2}\right)^{2}+\left(\sigma_{1}-\sigma_{3}\right)^{2}+\left(\sigma_{2}-\sigma_{3}\right)^{2}=f_{\mathrm{s}}^{2} \text {. }
$$

Mises yield condition of the steel tube which is considering tension in the hoop direction and compression in the axial direction can be simplified to

$$
\sigma_{1}^{2}+\sigma_{1} \sigma_{2}+\sigma_{2}^{2}=f_{\mathrm{s}}^{2}
$$

where, $\sigma_{1}$ is longitudinal pressure of the steel tube; $\sigma_{2}$ is circumferential pressure of the steel tube.

Having an explicit physical concept is the main advantage of Tresca yield condition. When having the order of the principal stresses, yield function is linear and have a simple form which is easy to calculate. However, the main disadvantage of this method is the fact that it ignores the contribution of intermediate principal stress in yielding process. When the order of the principal stress is unknown, having suitable the yield function would be difficult task. The Mises yield function is nonlinear and consider the contribution of intermediate principal stress in yielding process. The results concede with Mises yield condition and the difference between two of them is negligible.

\subsection{Derivation of axial bearing capacity of hollow circular CFST columns with circular inner steel tube}

The axial bearing capacity of circular hollow CFST columns with a single steel tube is studied. The cross section is shown in Fig. 1. The inner steel tube has a radially outward support effect on the sandwich concrete and has the same function as the concrete area of ordinary CFST columns, and both provide support for the sandwich concrete. The transverse deformation of the sandwiched concrete and the constraint of the outer steel tube is the main reason of having better bearing capacity of circular hollow CFST columns with circular inner steel tube comparing to the bearing capacity of circular hollow CFST columns. Most importantly, the axial load of CFST columns with circular inner steel tube is shared by the outer steel tube which is producing the confining effect and the sandwich concrete which is under confining effect of the inner steel tube.



Fig. 1 Circular hollow CFST columns with inner monolayer circular steel tube

According to the force analysis, the static equilibrium equation can be derived as

$$
N=\mathrm{A}_{\mathrm{c}} f_{\mathrm{c}}^{\prime}+\mathrm{A}_{\mathrm{s} 1} \sigma_{\mathrm{s} 11}+\mathrm{A}_{\mathrm{s} 2} f_{\mathrm{s} 2},
$$

by substituting the yield condition of concrete Eq. 1 into the Eq. $4 \mathrm{a}$ the equation can be expressed as

$$
N=\mathrm{A}_{\mathrm{c}} f_{\mathrm{c}}\left(1+k \frac{p}{f_{\mathrm{c}}}\right)+\mathrm{A}_{\mathrm{s} 1} \sigma_{\mathrm{s} 11}+\mathrm{A}_{\mathrm{s} 2} f_{\mathrm{s} 2}
$$

where, $A_{\mathrm{c}}$ is the area of the concrete; $f_{\mathrm{c}}$ is the compressive strength of the concrete; $p$ is the interaction between the outer steel tube and the concrete; $A_{\mathrm{s} 1}$ is the area of steel tube; $\sigma_{\mathrm{s} 11}$ is the longitudinal pressure of the outer steel tube; $A_{\mathrm{s} 2}$ is the area of the steel tube; $f_{\mathrm{s} 2}$ is the circumferential pressure of the inner steel tube; $k$ is the correlation coefficient of the core concrete which is 4 .

According to [8], the relationship between the lateral restraint of the steel tube and the hoop stress of the steel tube can be expressed as

$$
p=\frac{2 t_{1} \sigma_{\mathrm{s} 12}}{d_{1}}=\frac{\mathrm{A}_{\mathrm{s} 1} \sigma_{\mathrm{s} 12}}{2\left(\mathrm{~A}_{\mathrm{s} 1}+\mathrm{A}_{\mathrm{s} 2}+\mathrm{A}_{\mathrm{c}}+\mathrm{A}_{\mathrm{h}}\right)}
$$

where, $A_{\mathrm{h}}$ is the hollow area; $d_{1}$ is the diameter of the outer steel tube; and $t_{1}$ is the thickness of the outer steel tube.

First, by using the Mises yield condition, axial bearing capacity will be calculated. However, obtaining the analytical solution is impossible during the whole procedure. To derive the axial bearing capacity, the Tresca yield condition of the steel tube (Eq. 2d) was used. While the component is in limit state, the yield condition of the outer steel tube can be expressed as

$$
\sigma_{\mathrm{s} 12}+\sigma_{\mathrm{s} 11}=f_{\mathrm{s}} \text {. }
$$

By substituting the Eq. 5-6 into Eq. 4 the equation can be expressed as

$$
N=\mathrm{A}_{\mathrm{c}} f_{\mathrm{c}}+\mathrm{A}_{\mathrm{s} 2} f_{\mathrm{s} 2}+\frac{2 \mathrm{~A}_{\mathrm{c}}}{\left(\mathrm{A}_{\mathrm{s} 1}+\mathrm{A}_{\mathrm{s} 2}+\mathrm{A}_{\mathrm{c}}+\mathrm{A}_{\mathrm{h}}\right)} \sigma_{\mathrm{s} 12}
$$

the maximum value for the axial bearing capacity can be obtained when $\sigma_{\mathrm{s} 12}=f_{\mathrm{s} 1}$, where, $A_{\mathrm{h}}$ is the hollow area.

1) if $A_{\mathrm{c}}-A_{\mathrm{s} 1}-A_{\mathrm{s} 2}-A_{\mathrm{h}}>0$, with increasing value of $\sigma_{\mathrm{s} 12}$, the value of $N$ increases and the maximum value of $N$ can be obtained when $\sigma_{\mathrm{s} 12}=f_{\mathrm{s} 1}$ and it can be expressed as

$$
N=\mathrm{A}_{\mathrm{c}} f_{\mathrm{c}}+\mathrm{A}_{\mathrm{s} 2} f_{\mathrm{s} 2}+\frac{2 \mathrm{~A}_{\mathrm{c}}}{\left(\mathrm{A}_{\mathrm{s} 1}+\mathrm{A}_{\mathrm{s} 2}+\mathrm{A}_{\mathrm{c}}+\mathrm{A}_{\mathrm{h}}\right)} f_{\mathrm{s} 1} \cdot
$$

2) if $A_{\mathrm{c}}-A_{\mathrm{s} 1}-A_{\mathrm{s} 2}-A_{\mathrm{h}}<0$, with increasing value of $\sigma_{\mathrm{s} 12}$, the value of $N$ decreases and the maximum value of $N$ can be obtained when $\sigma_{\mathrm{s} 12}=0$, and it can be calculated by:

$$
N=\mathrm{A}_{\mathrm{c}} f_{\mathrm{c}}+\mathrm{A}_{\mathrm{s} 1} f_{\mathrm{s} 1}+\mathrm{A}_{\mathrm{s} 2} f_{\mathrm{s} 2} .
$$

According to the real situation, the axial bearing capacity of CFST columns with inner monolayer circular steel tube should be not less than the sum of the maximum bearing capacity of the components.

Above all, when $\psi \geq 0.5$

$$
N=\mathrm{A}_{\mathrm{c}} f_{\mathrm{c}}\left[1+\theta_{1}+\theta_{2}\right],
$$

when $\psi<0.5$ 


$$
N=\mathrm{A}_{\mathrm{c}} f_{\mathrm{c}}\left[1+2(1-\psi) \theta_{1}+\theta_{2}\right],
$$

where, $\theta_{1}$ is the confining parameter of the outer concrete to outer steel tube; $\theta_{2}$ is the capacity ratio of the inner steel tube and concrete without considering confinement effect; $1-\psi$ is the ratio of the concrete area and total area, where, $\quad \theta_{1}=\frac{\mathrm{A}_{\mathrm{s} 1} f_{\mathrm{s} 1}}{\mathrm{~A}_{\mathrm{c}} f_{\mathrm{c}}} \quad, \quad \theta_{2}=\frac{\mathrm{A}_{\mathrm{s} 2} f_{\mathrm{s} 2}}{\mathrm{~A}_{\mathrm{c}} f_{\mathrm{c}}}$, $\psi=\frac{\mathrm{A}_{\mathrm{h}}+\mathrm{A}_{\mathrm{s} 1}+\mathrm{A}_{\mathrm{s} 2}}{\left(\mathrm{~A}_{\mathrm{c}}+\mathrm{A}_{\mathrm{h}}+\mathrm{A}_{\mathrm{s} 1}+\mathrm{A}_{\mathrm{s} 2}\right)}$.

From the equation, it can be seen that: firstly, the axial bearing capacity of circular hollow CFST columns with inner steel tube and confining parameter have linear relationship. Secondly, the confining ability of steel tube to concrete is due to hollow ratio. The total confining reduction factor of hollow CFST columns with inner steel tube is regarded as $1-\psi$.

\section{Derivation of the unified equation}

According to the derivation for the axial bearing capacity of the different composite CFST columns in the section 1, the equivalent confining parameter of CFST columns is equal to the linear superposition of the confining parameter of each layer of steel tube. However, there exists a disadvantage: the equation for the axial bearing capacity of CFST columns with different cross-sections are different, which will result in a non-uniform bearing capacity equation for the composite CFST columns with the same properties. Therefore, the linear superposition of the equivalent confining parameter, combing the unified theory [10], can be used to write the unified equations for the axial bearing capacity with different cross-sections. The equation is an extension and supplement to the unified theory of CFST columns as well. The unified equation for the axial bearing capacity of the composite CFST columns can be expressed as

$$
\begin{gathered}
N=f_{\mathrm{c}}\left(1.212+B \theta+C \theta^{2}\right) A_{\mathrm{sc}}, \\
\mathrm{B}=\frac{0.176 f_{y}}{235}+0.974, C=\frac{f_{c}}{20.1}-0.0309^{[10]},
\end{gathered}
$$

where, $f_{c}$ is the axial compressive strength of concrete with no lateral pressure; $A_{s c}$ is the total area of the CFST section, which $A_{s c}=A_{c}+\sum_{i=1}^{n} A_{s i}$.

$N$ is the axial bearing capacity of CFST columns with multilayer non-concentric steel tube; $A_{c}$ is the total area of the concrete; $A_{s i}$ is the area of the ith steel tube; $f_{s i}$ is the yield strength of the ith steel tube; $\theta$ is the equivalent confining parameter.

The following two points are explained for Eq. 11: The confining parameter $\theta$ of hollow circular CFST columns with circular inner steel tube can be expressed as (only the hollow circular CFST columns with inner monolayer circular steel tube has been discussed)

if $A_{c} / A \geq 0.5$

$$
\theta=\frac{A_{c}}{A} \sum_{i}^{n} \frac{A_{s i} f_{s i}}{A_{c} f_{c}} ;
$$

if $A_{\mathrm{c}} / A=1$, the member is solid CFST column.

The axial bearing capacity of the member can be obtained according to the Eq. 11.

if $A_{c} / A<0.5$,

$$
N=f_{c} A_{c}+f_{s 1} A_{s 1}+f_{s 2} A_{s 2} .
$$

\section{Conclusion}

The equivalent confining parameter of hollow compound CFST columns is the linear superposition of each steel tube layers' confining parameter. The confining parameter of each steel tube layer is about area occupancy. When the concrete area is 0.5 times than the bounding area of the steel tube, the confining parameter of the steel tube should be considered. Otherwise, the confining parameter of the steel tube should not be considered, i.e., the steel tube only generates axial stress.

\section{Acknowledgment}

This study was founded by the National Natural Science Foundation of China（No 51578181）， Natural Science Foundation of Guangdong Province (No 2016A030313665). The authors would like to extend their appreciation to Shenzhen Carbon Storage Cement-based Materials Engineering Laboratory

\section{References}

1. Z. Tao, L.H. Han and H. Huang, China. Civ. Eng. J. 37(10), 41-51, (2004)

2. M.L. Lin and K.C. Tsai, Proc. Fir. Int. Conf. Steel. Compos. Struct. 1145-1152, (2001)

3. K. Uenaka, H. Kitoh and K. Sonoda. Thin-Walled Struct. 48(1), 19-24, (2010)

4. S. Wei, S.T. Mau, C. Vipulanandan, S.K. Mantrala, J. Struct. Eng. ASCE. 121(12), 1806-1814, (1995)

5. W.J. Pei, M.S Dissertation, Chang'an University, Xi'an, (2015).

6. J.R. Qian, Y. Zhang and X.D. Ji, J. Build. Struct. 32(12), 161-169, (2011)

7. A.A. Gvstev and W.B. Calculation of structural bearing capacity of limit equilibrium method (Architectural Engineering Press, Beijing, 1958)

8. X.X. Zha and H.J. Xu, J. Build. Struct. 36(supp11), 192-198, (2015)

9. B.Y. Xu and X.S. Liu, Elastic-Plastic application mechanics, (Tsinghua University Press, Beijing, 1995)

10. S.T. Zhong, The concrete-filled steel Tubular Structure, (Tsinghua University Press, Beijing, 2003) 